\title{
Personality and Self-Regulation
}

\section{Rick H. Hoyle*}

Because people are not in complete control of the physical and social environments they encounter in daily life, it is inevitable that discrepancies arise between what their identities, goals, and preferences lead them to expect or desire in specific situations and what transpires in those situations. People generally find such discrepancies at least mildly and temporarily unsettling, because they call into question their understanding of how the world works (or could work) or their understanding of their own goals, motives, or behavior. When these discrepancies arise, they generally are met with swift and decisive actions aimed at aligning expectations or desires and reality. These actions, collectively referred to as self-regulation, are the natural, often automatic response of healthy individuals to salient discrepancies between expectation and reality as they perceive it. They may involve cognition or behavior, and almost always are attended by affect.

Effective self-regulation is the bedrock of healthy psychological functioning. People who routinely are successful at self-regulation benefit from a sense of psychological stability and personal control that allows them to manage their perceptions of themselves and how they are perceived by others. Their behavior typically reflects salient goals and adopted standards of behavior. Departures from these desired states are handled smoothly and effectively. People who routinely fail at self-regulation enjoy none of the psychological benefits that derive from a sense of psychological stability and control and struggle with mild to severe forms of psychopathology. Effective self-regulation, by which people control their thoughts, feelings, and behaviors, is essential for adaptive functioning.

The recognition that self-regulation is of central importance in adaptive functioning has inspired a large literature on the antecedents, correlates, and consequences of

\footnotetext{
* During the writing of this chapter, the author was supported by grants P20-DA017589 and P30-DA023026 from the National Institute on Drug Abuse.
} 


\section{Rick H. Hoyle}

effective and ineffective self-regulation. Contributors to this literature represent the full range of subdisciplines within psychological science as well as other disciplines concerned with human behavior (e.g., sociology, education). In the psychological sciences, different perspectives and streams of research on self-regulation have been showcased in a number of edited volumes published within the last decade (e.g., Baumeister \& Vohs, 2004; Boekaerts, Pintrich, \& Zeidner, 2000; Cameron \& Leventhal, 2003; de Ridder \& de Wit, 2006; Heckhausen \& Dweck, 1998).

Despite the impressive size and breadth of the literature on self-regulation in psychological science and related disciplines, relatively little research or theorizing (especially in the adult literature) has targeted the intersection of self-regulation and personality processes. As such, research on personality structure and process rarely reflects the rich detail of models of self-regulatory processes, and research on the selfregulatory processes rarely addresses the fact that some portion of those processes is a reflection of stable tendencies of individuals. The primary aim of this handbook is to bridge the personality and process-oriented literatures on self-regulation by showcasing programs of research that draw from and speak to both perspectives.

In this opening chapter, I begin by discussing personality and information-processing perspectives on self-regulation. Next, I describe ways in which the personality and information-processing perspectives might be integrated. These range from methodological approaches, in which constructs representing the two perspectives are examined through integrated data-analytic strategies, to conceptual approaches, in which the two perspectives are unified in a holistic theoretical model of self-regulation. In the final section of the chapter, I preview the individual contributions that constitute the remainder of the handbook, which is organized in three conceptually coherent but overlapping parts: the emergence and early expression of variability in self-regulation; self-regulation as a process that plays out in the context of normal adult personality; and individual differences in the components, styles, and effectiveness of self-regulation.

\section{Temperament and Personality Perspectives}

The characteristic means by which people self-regulate and the routine success or failure they experience are reflected in personality traits. Many of these traits are rooted in temperament, which manifests early in life. Despite the obvious continuity between temperament and personality, the literatures on these two manifestations of personhood are relatively distinct; thus, they are summarized separately in this section.

\section{Temperament Constructs}

The basic elements of the self-system and the capacity to self-regulate begin to emerge early in life. For example, variation in the ability to inhibit behavior stabilizes 
by about one year of age (Kagan, 1997). The ego-the psychological structure and processes through which people relate to their social and physical environmentundergoes differentiation and change as young children mature (Loevinger, 1976). In terms of self-regulation, the developing individual becomes increasingly more able to delay gratification and increasingly less prone to act impulsively or in response to external pressure (Hy \& Loevinger, 1996). With the emergence of self-awareness and internalized standards of behavior comes the capacity to self-regulate.

A temperament construct with clear implications for self-regulation is effortful control, defined as the "ability to inhibit a dominant response to perform a subdominant response, to detect errors, and to engage in planning” (Rothbart \& Rueda, 2005, p. 169). Although specific constructs and labels vary across models of temperament, most include two broad factors that reflect the tendency toward a dominant response of approach or avoidance. Through the exercise of effortful control, children are able to inhibit these dominant responses when they would conflict with an activity in which they are engaged. Individual differences in effortful control begin to emerge by two years of age and by four years of age are temporally stable (Kochanska, Murray, \& Harlan, 2000). Effortful control is a precursor to the constraint dimension in adult models of personality.

A related temperament construct is behavioral inhibition, which focuses on variation in children's reactions to unfamiliar or unexpected stimuli. In the presence of such stimuli, children as young as one year of age who are behaviorally inhibited exhibit stress and behavioral restraint. The neurophysiology of behavioral inhibition indicates overactivity in brain regions associated with fear (Fox, Henderson, Marshall, Nichols, \& Ghera, 2005). Thus behaviorally inhibited children are faced with the regulatory challenge of managing fear and anxiety in the face of the unexpected. Because a stimulus for self-regulation is unexpected feedback from the environment (Duval \& Wicklund, 1972), behaviorally inhibited individuals face the challenge of managing such feedback while also managing the fear and anxiety such stimuli invoke.

These and other temperament constructs influence the emergence and development of self-regulation and underlie personality traits relevant to adult self-regulation. Although a large number of personality traits have some relevance for adult selfregulation, those that follow most clearly from temperament and are most likely to appear in major models of personality can be grouped under the general headings of conscientiousness and impulsivity.

\section{Conscientiousness and Related Constructs}

Among the higher-order dimensions of personality, conscientiousness is the most clearly relevant for self-regulation. Although defined somewhat differently in lexical and psychometric models, conscientiousness generally concerns the ways in which people characteristically manage their behavior. People who are high on conscientiousness 
are confident, disciplined, orderly, and planful, whereas people who are low on conscientiousness are not confident in their ability to control their behavior, and are spontaneous, distractible, and prone to procrastinate (Costa \& McCrae, 1992). In research linking conscientiousness to behavior, the more narrowly focused facets underlying the domain are emphasized (Paunonen \& Ashton, 2001). The facetscompetence/self-efficacy, orderliness, dutifulness, achievement striving, self-discipline, and deliberation/cautiousness - reflect different behavioral tendencies characteristic of successful self-regulation (Roberts, Chernyshenko, Stark, \& Goldberg, 2005).

A related higher-order dimension of personality is constraint, which reflects well the temperament trait of behavioral inhibition (Tellegen, 1982). Facets of constraint focus on the tendency to inhibit the expression of impulse and emotion (control), behavior at odds with social convention (traditionalism), and risk taking (harm avoidance). As with conscientiousness, in research on self-regulation constraint is best considered in terms of its facets.

\section{Impulsivity and Related Constructs}

As a trait, impulsivity is the tendency to act without thought or planning. It is evident in early childhood (Clark, 1993) and has a strong neurobiological signature (Spinella, 2004). Impulsive behaviors typically are quick, often inappropriate, and frequently risky. People who are highly impulsive are prone to a host of high-risk behaviors characterized by poor self-control (e.g., Hoyle, Fejfar, \& Miller, 2000; Krueger, Caspi, Moffitt, White, \& Slouthamer-Loeber, 1996; Wulfert, Block, Ana, Rodriguez, \& Colsman, 2002). Although impulsivity can be assessed, and often is studied, as a trait, it also appears as a constituent of broader traits and domains of personality such as extraversion and psychoticism in the P-E-N model (Psychoticism, Extraversion, and Neuroticism; Eysenck, 1990), conscientiousness in the five-factor model (Costa \& McCrae, 1992), impulsive sensation seeking in the alternative five-factor model (Zuckerman, Kuhlman, Joireman, Teta, \& Kraft, 1993), and the behavioral approach system in Gray's (1994) neurophysiological model. Impulsivity typically is cast as a behavioral liability; however, in conditions that do not allow for forethought or planning, impulsivity can be an asset (Dickman, 1990). In either case, behavior is not consciously regulated by the individual, and therefore the process models described below routinely do not apply.

The idea that self-control is not always adaptive is apparent in the ego control construct (Block \& Block, 1980). Ego control is defined as the "expression or containment of impulses and desires" (Letzringa, Block, \& Funder, 2004). An important feature of this conceptual model is the notion that individuals can be overcontrolled as well as undercontrolled. Individuals who are undercontrolled do not suppress emotional expression and behavior even when so doing would violate personal or social standards of appropriateness. In terms of self-regulation, they do not exercise self-denial, are emotionally unstable, and are easily distracted. Individuals who are overcontrolled 
excessively inhibit emotional expression and behavior. In terms of self-regulation, they are rigidly organized, likely to exercise self-denial when it is not necessary to do so, and persist at tasks when it is no longer productive to do so. According to the model, although the self-regulatory styles of undercontrolled and overcontrolled people ordinarily are maladaptive, under certain conditions they are advantageous. For instance, the self-discipline and persistence characteristic of overcontrolled people would be beneficial when productivity under pressure is required. The spontaneity and emotional expressiveness of undercontrolled people would play well in many social settings. On average, however, a measured degree of ego control results in the most adaptive self-regulation.

Related to impulsivity and ego control is the construct of disinhibition, the inability to control demands on attention, cognition, and behavior that interfere with desired behavior. Specifically, disinhibition involves an inability to prevent interference from competing stimuli, irrelevant thoughts or demands on attention, and reflexive and automatic behaviors. Alternatively, disinhibition can be viewed as a failure of the behavioral inhibition system, which evaluates the relevance of stimuli in terms of what is expected given the situation, responds to inhibitory signals associated with stimuli that are unexpected, and motivates behavior aimed at reducing the influence of those stimuli on cognition, motivation, and behavior (Gray, 1991). In terms of selfregulation, people high in disinhibition are likely to struggle to stay on track in the pursuit of important goals or outcomes.

This selective review of temperament and personality constructs relevant to selfregulation suggests how, and to some extent why, people vary in terms of how they self-regulate, how often they self-regulate, and the degree of success or failure at selfregulation they routinely experience. The personality perspective on self-regulation, exemplified by these constructs, suggests underlying neurophysiological influences and positions self-regulation in the broader context of differences in temperament and personality. With rare exception, however, the personality perspective provides little insight into the cognitive, affective, and behavioral processes that define a specific instance of self-regulation.

\section{Information-Processing Perspective}

An alternative perspective on self-regulation focuses on the specific processes by which information about the self is processed and the implications of that processing for motivation and behavior. The original model of this type, which is prototypic of models that take this perspective, was described within objective self-awareness theory (Duval \& Wicklund, 1972). According to the theory, when attention is directed toward the self an evaluation ensues in which current self-representation is compared against internalized standards of correctness as reflected in an ideal self-representation. 
This comparison yields affect, typically negative affect stemming from the unfavorable discrepancy between current and ideal self-representations. The negative affect motivates behavior aimed at reducing the discrepancy, either through behavior designed to change current self-representation to more closely approximate ideal self-representation or to direct attention away from the self. Characteristics of this conceptualization that are apparent in other information-processing models of selfregulation include self-awareness, comparison of current self-representation with a behavioral standard, and the management of any unfavorable discrepancy between self-representation and the standard (e.g., Carver \& Scheier, 1981; Higgins, 1987; Pyszczynski \& Greenberg, 1987). In these models, self-regulation has succeeded when self-representation and the salient behavioral standard are reconciled and attention shifts from the self back to the environment.

Related models offer greater detail in terms of the process and its components. Perhaps the most influential of these models is the control-process model of self-regulation (Carver \& Scheier, 1981). This model places less emphasis on self-awareness and negative affect and greater emphasis on sources of behavioral standards and the process by which the discrepancy between those standards and current self-representation are managed. Embellishments to the model focus on the awareness of the rate at which discrepancies are reduced and the implications of this awareness for affect (Carver \& Scheier, 1990). Self-discrepancy theory focuses more specifically on sources of behavioral standards, distinguishing between ideal and ought self-representations and detailing the emotions that arise when each is contrasted with current selfrepresentation (Higgins, 1987). As a group, these models offer a rich and detailed account of what people are doing and feeling when they are self-regulating.

Fundamental to these models is the assumption that self-regulation is conscious and effortful. The assumption of consciousness is particularly evident in models that accord self-awareness a central role in the process (e.g., Duval \& Wicklund, 1972). The assumption of effort is evident in that all of the models assume an unsatisfactory state that typically is overcome through cognitive or behavioral strategies. This assumption is underscored and, to some extent, validated by accumulating evidence that people are less effective at self-regulation when their ability to expend effort on it has been compromised (Muraven \& Baumeister, 2000).

The extent to which these assumptions are, in fact, fundamental has been called into question by a growing body of evidence indicating that some portion of people's goaloriented behavior is nonconscious and automatic (Bargh \& Williams, 2006). Moreover, the influence of goals activated outside of consciousness on behavior may equal the influence of goals activated in a conscious manner (Bargh, Gollwitzer, Lee-Chai, Barndollar, \& Troetschel, 2001). Whether the process initiated by nonconscious activation is similar to the conscious process described earlier is unclear. Furthermore, it is not clear whether activation of all behavioral standards would initiate nonconscious self-regulation, or whether goals are unique in this regard. Nonetheless, it is evident that, at least some of the time, the regulation of behavior requires neither consciousness nor effort. 
Models of self-regulation in the information-processing tradition address important concerns regarding what the process of self-regulation entails. They describe stimuli that initiate the process, components of the process, how the process unfolds, and, ultimately, the conditions that cause the process to terminate. Although the informationprocessing perspective offers a detailed account of the process of self-regulation, it offers little in the way of explaining the developmental origins of this process and variation across people in the characteristic ways the process unfolds.

\section{Integrating the Perspectives}

Although the personality and information-processing perspectives on self-regulation have yielded important empirical and theoretical advances, each offers only a partial explanation of self-regulation. Personality accounts are generally decontextualized, and processing accounts generally ignore fundamental differences between people. A fuller account of self-regulation would be provided by an integration of these complementary perspectives. Elsewhere, I have presented a general framework for integrating trait and process variables in the study of behavior (Hoyle, 2000). In the remainder of this section I draw on that framework to suggest three ways in which the personality and information-processing perspectives on self-regulation could be integrated.

\section{Distal-Proximal Approach}

One means of integrating the personality and information-processing approaches focuses on the causal order of their influence on behavior. In this approach the initial focus is a personality-behavior association. Because personality traits are preexisting characteristics of individuals, the assumption of this approach is that the influence of personality on a specific instance of behavior unfolds in a situated process. In such a model, personality traits are distal influences that operate on behavior through a proximal, online process. Research that exemplifies this approach is rare within the self-regulation literature (for an example, see Tobin, Graziano, Vanman, \& Tassinary, 2000). To some extent, this relative lack of distal-proximal research is not surprising because of how studies inspired by the personality and information-processing perspectives typically are done. Research from the trait perspective typically relies on unsituated measurement of traits and summary measures of behavior. Research from the information-processing perspective typically concerns specific instances of a specific behavior in a controlled setting. Investigators working from the informationprocessing perspective are best situated to integrate perspectives using this approach, needing only to measure relevant traits, preferably before and in a different setting from the controlled setting in which processing and behavior are observed. 


\section{Conditional Influence Approach}

An alternative means of integrating the two approaches is to examine self-regulatory processing at different levels of temperament or personality traits. For such studies to be successful, neither the self-regulatory process nor the trait on which it is conditioned need to have previously been linked to the behavior. Indeed, it is possible that the consideration of a link between self-regulation and behavior at different levels of a personality trait would reveal an association not evident when the link is evaluated in an unconditional model. In this integrative approach, the effect of the personality trait on the behavior is not of primary interest; thus, traits need not belong to the category of personality traits directly relevant to self-regulation (although frequently they will). An example of such a trait is self-monitoring. Individuals high in selfmonitoring are more likely to experience public self-awareness and reference social standards, whereas individuals low in self-monitoring are more likely to experience private self-awareness and reference personal standards (Hoyle \& Sowards, 1993). Thus key aspects of the self-regulatory process are conditional on self-monitoring. The implementation of research consistent with this approach would not differ from the implementation of research consistent with the distal-proximal approach. The two approaches differ in terms of the assumed relation between personality and processcausal in the distal-proximal model, no relation assumed in the conditional modeland the assumed relation between personality, process, and the behavior-both personality and process causally related to behavior in the distal-proximal model, no relation between personality and behavior assumed in the conditional model.

\section{Conceptually Integrated Approach}

In the distal-proximal and conditional approaches to integrating the personality and information-processing perspectives on self-regulation, the constructs and processes are separately measured or operationally defined, then integrated in the statistical modeling of the data. A more profound integration would be conceptual models that simultaneously implicate personality traits and information processing in such a way that each accounts for the other. At the personality level, such efforts have been attempted for impulsivity (Carver, 2005), narcissism (Morf \& Rhodewalt, 2001), and selfmonitoring (Hoyle \& Sowards, 1993). Dynamic models of personality (e.g., Mischel, 2004), which define personality as invariance in situated emotion, thought, and behavior, hold promise for a broader integration of the personality and informationprocessing perspectives (see also Cervone, 2004; Morf, 2006). The development of such models for self-regulation requires the thoughtful integration of temperament or personality and information-processing constructs in such a way that personality can be understood in terms of process and processes can be understood as expressions of personality. 


\section{Overview of the Handbook}

Chapters in Part I of the handbook explore the emergence and development of the capacity for self-regulation during infancy and early childhood. In Part II, chapters present conceptual models and empirical findings relevant to the integration of basic personality processes and self-regulatory processes in normal adults. The final set of chapters, in Part III, focuses on a range of individual differences that distinguish styles of regulation and their relative effectiveness in the course of everyday life.

\section{Temperament and Early Personality}

Eisenberg, Eggum, Vaughan, and Edwards open Part I with a chapter on the temperamental bases of self-regulation. They present key findings from an impressive program of research that spans more than 15 years. They describe a multifaceted model of effortful control - an aspect of temperament - and discuss the association of the facets of effortful control with internalizing and externalizing behavior and with emotionality in toddlers and young children. They compare these relations with those involving reactive control, which differs from effortful control in that it is relatively automatic. This distinction between voluntary and involuntary control processes highlights a useful distinction that has had only a modest influence on models of self-regulation in adulthood (cf. Bargh \& Chartrand, 1999). Eisenberg et al. close by pointing out the need for more precise measures of the components of temperament relevant for self-regulation that would facilitate research on causal processes in the relations they have observed as well as studies of the relations between the components as they change with age.

A landmark study in the literature on self-regulation during childhood is Mischel's (1958) experimental study of preference when given a choice between an immediate, but relatively small, reward versus a delayed, but relatively larger, reward. The seminal study showed that young children are increasing able to delay gratification by choosing the larger reward despite the temptation of an immediate reward. Tobin and Graziano review 50 years of research building on this finding. They organize the sprawling literature on delay of gratification using a rubric that both reveals the lack of coherence of this literature and sets the stage for a proposed new model of the processes at play in delay of gratification. Their model is integrative and well-grounded in basic research on perception, valuation, and decision making, setting the stage for a new generation of research on a prototypic instance of self-regulated behavior.

Blair, Calkins, and Kopp examine the relation between self-regulation in young children and their early performance in school. They focus on the role of early biological functioning as it affects executive functioning in the development of effective strategies for managing behavior and emotions. Blair et al. note that, although the components of self-regulation were not routinely assessed in evaluations of preschool programs, it 
is likely that the positive effects of those programs on adjustment and well-being can be attributed to their contribution to the development of adequate self-regulatory skills and strategies. They highlight findings from recent evaluations of a new preschool program that indicate clear effects on executive functioning and self-control. Their analysis provides strong support for early interventions that attend to biological functions that serve as a foundation for effective self-regulation in the academic context.

The final chapter in Part I, contributed by McDermott and Fox, concerns the role of response monitoring in self-regulation. Consistent with the analysis by Blair et al., these authors draw attention to the underlying neurobiology as it develops during early childhood. Building on findings from imaging, physiological, and behavioral studies of response monitoring and related constructs, the authors make a strong case for focusing on response monitoring in evaluations of effectiveness at self-regulation and attempts to improve self-regulation. Their analysis concludes by relating response monitoring to aspects of temperament and showing that whether response monitoring is adaptive depends on where young children stand on temperamental traits such as fearfulness.

\section{Personality Processes}

Morf and Horvath fittingly open Part II, which focuses on personality processes, by discussing a model that integrates the trait and information-processing perspectives on self-regulation within a general, dynamic personality framework. They define personality as the individual's unique approach to constructing and maintaining selfrepresentations through intrapsychic and, mostly, interpersonal self-regulatory processes. A core component of their model is the regularity in contingencies between situations and individuals' responses to them, which give rise to "signatures of the self." They illustrate the dynamic components of their model by selectively applying it to personality traits such as rejection sensitivity and narcissism. Morf and Horvath's chapter sets the stage for the remainder of Part II by demonstrating the conceptual integration of trait and information processing perspectives on self-regulation in a coherent, dynamic model of personality.

Whereas Morf and Horvath describe a model in which personality emerges from patterns of situated self-regulation, McCrae and Löckenhoff begin with the dominant model of personality, the five-factor model, and locate characteristic patterns of selfregulation within it. Specifically, the authors draw on five-factor theory to provide an account of how individual differences in self-regulation emerge from basic aspects of personality. By influencing the behavioral standards that guide self-regulation, affective reactions during self-regulation, and mechanisms by which experience is reconciled with standards, a person's standing on the five principal personality factors and their constituents define the psychological context within which self-regulation takes place. Like Morf and Horvath, McCrae and Löckenhoff persuasively argue that personality and self-regulation are entwined. A fundamental difference between the two accounts is the question of which gives rise to the other. Longitudinal research 
that begins with young children, such as that featured in Part I of the handbook, will be required to determine whether, or perhaps when, one takes precedence over the other.

Niemiec, Ryan, and Deci discuss the concept of autonomy in self-regulation terms. Their analysis touches on a core assumption of many models of self-regulation - that individuals exercise will in choosing among behaviors and outcomes. In their view, true self-regulation implies autonomy, which varies from one action to the next. Furthermore, people vary in their tendency to function autonomously; that is, they vary in the extent to which they regulate their own behavior. The authors offer a critique of theoretical perspectives that question the possibility of autonomy and, therefore, self-regulation. By disentangling independence and autonomy, they show how behavior contingent on the environment can, nonetheless, be autonomous if the individual exercises choice in allowing for the environmental influence. Similarly, automatized behaviors can be autonomous if, upon reflection, they would be chosen by the individual and, if desired, could be overridden. Defined in this way, autonomy is essential for self-regulation and, more broadly, for healthy psychological functioning.

Sansone, Thoman, and Smith describe their work on the self-regulation of motivation. In their model, while individuals are engaged in goal-directed behavior motivated by personal and/or situational characteristics, their motivation might increase or decrease as a function of their experience of engaging in the behavior. Of particular import is the degree to which the behavior is experienced as interesting. They specifically consider occasions when motivation provided by personal or situational characteristics is high, but interest is low. It is under these conditions that individuals might sustain the behavior by increasing interest through self-regulation. They review a host of studies that illustrate the role of personality in when and how interest is self-regulated. They illustrate the role of interest regulation in two important contexts - career choice and relationship maintenance. Sansone et al.'s work exemplifies the integration of the personality and information-processing perspectives on self-regulation through the conditional influence approach described earlier.

Karoly describes his conceptual model of self-regulation and reviews research inspired by the model. As in the previous chapters in Part II, the author argues that, to be fully understood, models of self-regulation must account for characteristics of the individual as they are manifest and operate in situational context. A strength of Karoly's model is its specificity, both in terms of what self-regulation is and what it is not. The goal construct is central in his model and is specified and assessed at a level of detail unmatched by other accounts of goal pursuit. Karoly illustrates the usefulness of this model for understanding specific and consequential goal-guided activities such as pain management, physical exercise, and academic performance. Theorydriven measurement is a centerpiece of Karoly's work, and he presents compelling results of work that makes use of measurement tools design to capture the richness of goals and goal-related thoughts and behaviors. These measures exemplify the author's assertion that self-regulation is complex and multilayered, and that empirical efforts to understand self-regulation ought to be designed in such a way that they capture this complexity and richness. 
In the final chapter in Part II, DeWall, Baumeister, Schurtz, and Gailliot discuss the implications of variability in the capacity for self-regulation for the expression and influence of personality traits. They liken the capacity for self-regulation to strength or energy such as that generated by a muscle. They review evidence indicating that, as with muscular strength, this capacity is limited; thus it can be exhausted, leading to ego depletion and consequent failures of self-regulation. They reason that when the capacity for self-regulation is compromised, the influence of personality on behavior may be strengthened or weakened. For instance, when social convention runs contrary to what personality might dictate, ego depletion, by undermining the capacity to follow social convention, should result in pronounced effects of personality on behavior (cf. Caspi \& Moffitt, 1993). Conversely, when the expression of a personality trait involves self-regulation, ego depletion should thwart that expression, resulting in a reduction in the influence of personality on behavior. DeWall et al. present data from a large number of studies to illustrate these and other conditions under which ego depletion strengthens or weakens the expression and influence of personality. Their work is prototypic of the conditional influence approach to integrating personality and self-regulation described earlier in this chapter.

\section{Individual Differences}

Ilkowska and Engle begin Part III, which concentrates on individual differences relevant to self-regulation, by drawing our attention to variability in a fundamental aspect of information processing: working memory. After defining the working memory system and its functions, the authors describe research showing that, as children's working memory develops, their effectiveness at self-regulation improves. They also show that variability in working memory capacity in adulthood is associated with various aspects of the information processing involved in self-regulation. Personality and social psychologists who study self-regulation will find particularly useful a section of the chapter on measuring working memory capacity. In the latter half of the chapter, the authors draw on a number of literatures to show the link between working memory and a host of problem behaviors and behavioral deficits typically viewed as resulting from poor self-regulation.

Scholer and Higgins provide an overview of regulatory focus theory, highlighting two fundamentally different forms of self-regulation. Self-regulation from a promotion orientation involves striving for ideals through accomplishment and growth, whereas self-regulation from a prevention orientation involves fulfilling duties and obligations through safe and responsible behavior. Importantly, although individuals vary across situations in their characteristic orientation, situational pressures can cause them to self-regulate in ways that are not characteristic of them. Because individuals can be shifted from one orientation to the other, the literature inspired by regulatory focus theory includes, in addition to studies in which regulatory focus is measured, experiments in which individuals are randomly assigned to a promotion or prevention 
orientation. Scholer and Higgins draw on both types of studies to provide a detailed account of how promotion- and prevention-focused self-regulation operate in circumstances that require self-regulation (e.g., failure, temptation, group dynamics). A key feature of their model, upheld by a growing empirical literature on regulatory focus, is that, generally speaking, neither orientation is superior to the other. In the best case, individuals self-regulate from the orientation that best matches current situational pressures.

The chapter by Maddux and Volkmann focuses on self-efficacy, a highly influential construct that captures variation in beliefs about what one can and cannot do in certain conditions. Self-efficacy differs from other individual differences covered in Part III of the handbook in its specificity. Self-efficacy beliefs refer to specific behaviors and arise from direct and indirect experience with the behavior. Although self-efficacy beliefs are behavior specific, the likelihood of developing strong self-efficacy beliefs can be attributed, in part, to stable traits. The authors review research that points to a number of basic personality dimensions associated with the development of self-efficacy beliefs. A key contribution of the chapter is their discussion of selfefficacy beliefs as they influence the process of self-regulation at different stages. They conclude the chapter with a section on collective efficacy, a group's shared beliefs about its competencies, introducing the term "collective regulation" to refer to the members of a group working together to pursue shared goals.

Jostmann and Koole discuss self-regulation as action control, presenting a continuum that, at its extremes, defines two orientations to self-regulation in demanding situations. Individuals with an action orientation readily develop intentions to act so as to manage situational demands, whereas individuals with a state orientation are indecisive and hesitant in demanding situations. Like the promotion and prevention orientations outlined in regulatory focus theory, individuals differ reliably in their tendency to adopt one or the other orientation but could, in specific situations, adopt either orientation. According to the authors, high demands challenge working memory and related processes necessary for effective self-regulation. Individuals with an action orientation are able to shield against these challenges - using cognitive, affective, and behavioral strategies - and therefore manage high demands in ways that individuals with a state orientation cannot. The authors close with a discussion of practical strategies available to action- and state-oriented individuals for managing demanding situations.

Magen and Gross offer a systematic analysis of self-control in the face of temptation. Drawing on extant models of self-regulation and emotion regulation, they propose a process model of self-control. They use relatively common temptation situations to highlight components of the process prescribed by their model. They propose an interplay between personality and the process of self-control. Personality influences both the types of objects and activities that are tempting to the individual and the self-control strategies they invoke. At the same time (and consistent with Morf and Horvath's analysis in Part II), characteristic strategies for exercising self-control in the face of temptation influence personality. The authors draw on a variety of 
literatures in personality and self-regulation in support of each step of the proposed process.

Kruglanski, Orehek, Higgins, Pierro, and Shalev define self-regulation in goalpursuit terms, highlighting two fundamental aspects of self-regulation: assessment and locomotion. Assessment concerns processes associated with comparison in selfregulation; specifically, comparisons between alternative goals or means to achieving goals. Locomotion refers to processes in self-regulation that involve moving from the current state toward another state. In regulatory mode theory, these modes are orthogonal; that is, concern for one has no implications for concern for the other. Temperament and experience govern the degree to which individuals differ in their concern for each in the process of self-regulation. In terms of goal pursuit, high levels of locomotion are associated with preferences for activity, and high levels of assessment are associated with preferences for evaluation of alternatives. Although some goal pursuits emphasize one over the other, in general, goal pursuit is most effective when the two modes are effectively implemented. The authors illustrate these modes and the relative effectiveness of the various combinations of preferences for them by reviewing their accumulated work on individual and interpersonal goal pursuits. They also discuss research demonstrating the value of a regulatory mode analysis for performance and change in organizations and cultural differences.

Crocker, Moeller, and Burson draw attention to the incompatibility of selfregulation devoted to managing self-esteem and self-regulation focused on achieving important long-term goals. They refer to a focus on self-esteem maintenance as egosystem motivation and argue that, because of the emotions it entails, it occupies attention, motivation, and cognitive resources that might otherwise be used in the pursuit of goals that focus away from the self and toward others. They present findings from their research program on contingencies of self-esteem that illustrate the deleterious effects of the chronic and situational pursuit of self-esteem-low intrinsic motivation, high stress, and premature abandonment of relevant activities. Ecosystem motivation, in contrast, encompasses a concern for others and self in relation to others. It involves less emotion than egosystem motivation (though it is not free of emotion), and is characterized by self-regulation that is more effective and not an impediment to supportive relationships with others. They present findings from new research on the degree to which the tendency to pursue compassionate goals - those that emphasize constructiveness and support of others - is associated with improved self-regulation in the pursuit of personal goals.

VanDellen, Bradfield, and Hoyle continue the focus on self-esteem and selfregulation by examining the self-regulation of state self-esteem as a function of trait levels of self-esteem. They argue that, unlike trait self-esteem, which is quite stable across the lifespan, state self-esteem varies from moment to moment. Because selfregulation is prompted by discrepancies between expectations and reality, the strongly positive view of self characteristic of individuals high in trait self-esteem and the likelihood of social feedback that does not support this view ensures that they must routinely manage their state self-esteem through self-regulation. VanDellen et al. 
present findings showing that state self-esteem is particularly likely to fluctuate in social situations that are unpredictable and uncontrollable. They then review findings from two lines of research showing that high self-esteem people engage in cognitive and affective strategies aimed at maintaining a positive view of themselves in the moment.

Strauman and Wilson draw on findings from a wide range of traditions, including animal models and human brain imaging, to explore similarities and differences between models of approach and avoidance in goal pursuit. They begin by outlining two levels of analysis at which approach and avoidance tendencies might be described. Description at the biobehavioral level, as exemplified in models of behavioral activation and inhibition, focuses on early appearing individual differences that are, at least in part, heritable and that focus on the brain. Description at the social-cognitive level, as exemplified in regulatory focus theory, focuses on individual differences in information processing as they play out in social environments. The authors conclude that these levels represent two sets of processes that are activated by different stimuli but often function simultaneously, though not necessarily with the same orientation. In their brain imaging research, they indeed find that different neural substrates underlie the two levels of approach and avoidance. The chapter concludes with a discussion of the value of exploring self-regulation processes as they manifest at multiple levels of analysis.

Leary, Adams, and Tate fittingly conclude the handbook by proposing a strategy for managing situations in which attempts at self-regulation produce undesired outcomes. Examples include increased frequency of thoughts one is trying to suppress, overeating by individuals on a diet, and poorer sleep by individuals who try to control their sleep. To combat these ironic effects, Leary et al. propose a novel strategy-hypoegoic self-regulation. Sometimes hypoegoic states, characterized by low self-awareness and/or heightened focus on concrete behaviors in the present moment, occur spontaneously, as in the case of the performance of a well-learned behavior and the state of flow. Hypoegoic self-regulation is the intentional effort to produce or prolong hypoegoic states. This regulation can involve taking steps to reduce selfawareness or taking steps to focus on concrete behaviors in the present. Leary et al. describe strategies for pursuing either route to a hypoegoic state. For instance, selfawareness can be reduced through extensive practice or meditation. A focus on concrete behavior can be promoted by stimulating a focus on how, rather than why, a behavior is enacted or by training focus narrowly on behavior in the present moment (e.g., mindfulness). Leary et al. conclude by reviewing a series of individual differences likely to be associated with the ability to experience hypoegoic states. This novel conceptualization suggests that, under certain conditions, the most successful selfregulation strategy is not to self-regulate.

This handbook comprises a strong set of contributions from scholars at the forefront of the current wave of interest in self-regulation. They present findings from productive research programs that focus on self-regulatory processes while attending to individual variation in how those processes unfold. I hope this volume inspires deeper 
consideration of self-regulatory processes by temperament and personality researchers, and a better accounting for personality by social-cognitive researchers, as they develop new models and approaches to the study of self-regulation.

\section{References}

Bargh, J. A., \& Chartrand, T. L. (1999). The unbearable automaticity of being. American Psychologist, 54, 462-479.

Bargh, J. A., Gollwitzer, P. M., Lee-Chai, A. Y., Barndollar, K., \& Troetschel, R. (2001). The automated will: Nonconscious activation and pursuit of behavioral goals. Journal of Personality and Social Psychology, 81, 1014-1027.

Bargh, J. A., \& Williams, E. L. (2006). The automaticity of social life. Current Directions in Psychological Science, 15, 1-4.

Baumeister, R. F., \& Vohs, K. D. (Eds.). (2004). Handbook of self-regulation: Research, theory, and applications. New York: Guilford Press.

Block, J. H., \& Block, J. (1980). The role of ego-control and ego-resiliency in the organization of behavior. In W. A. Collins (Ed.), Development of cognition, affect, and social relations: The Minnesota symposium on child psychology (vol. 13, pp. 39-101). Mahwah, NJ: Erlbaum.

Boekaerts, M., Pintrich, P. R., Zeidner, M. (Eds.) (2000). Handbook of self-regulation. San Diego, CA: Academic Press.

Cameron, L. D., \& Leventhal, H. (Eds.). (2003). Self-regulation of health and illness behaviour. London: Routledge.

Carver, C. S. (2005). Impulse and constraint: Perspectives from personality psychology, convergence with theory in other areas, and potential for integration. Personality and Social Psychology Review, 9, 312-333.

Carver, C. S., \& Scheier, M. F. (1981). Attention and self-regulation: A control-theory approach to human behavior. New York: Springer.

Carver, C. S., \& Scheier, M. F. (1990). Origins and functions of positive and negative affect: A control-process view. Psychological Review, 97, 19-35.

Caspi, A., \& Moffitt, T. E. (1993). When do individual differences matter? A paradoxical theory of personality coherence. Psychological Inquiry, 4, 247-271.

Cervone, D. (2004). The architecture of personality. Psychological Review, 111, 183-204.

Clark, L. A. (1993). Schedule for nonadaptive and adaptive personality (SNAP). Minneapolis: University of Minnesota Press.

Costa, P. T., Jr., \& McCrae, R. R. (1992). Revised NEO personality inventory (NEO PI-R) and the NEO five-factor inventory (NEO-FFI) professional manual. Odessa, FL: Psychological Assessment Resources.

de Ridder, D., \& de Wit, J. (Eds.). (2006). Self-regulation in health behavior. New York: Wiley.

Dickman, S. J. (1990). Functional and dysfunctional impulsivity: Personality and cognitive correlates. Journal of Personality and Social Psychology, 58, 95-102.

Duval, S., \& Wicklund, R. A. (1972). A theory of objective self-awareness. New York: Academic Press.

Eysenck, H. J. (1990). Biological dimensions of personality. In L. A. Pervin (Ed.), Handbook of personality: Theory and research (pp. 244-276). New York: Guilford. 
Fox, N. A., Henderson, H. A., Marshall, P. J., Nichols, K. E., \& Ghera, M. M. (2005). Behavioral inhibition: Linking biology and behavior within a developmental framework. Annual Review of Psychology, 56, 235-262.

Gray, J. A. (1991). Neural systems, emotion, and personality. In J. Madden (Ed.), Neurobiology of learning, emotion, and affect (pp. 273-306). New York: Raven Press.

Gray, J. A. (1994). Framework for a taxonomy of psychiatric disorder. In H. M. Van Goozen, N. E. Van De Poll, \& J. A. Sergeant (Eds.), Emotions: Essays on emotion theory (pp. 29-59). Mahwah, NJ: Erlbaum.

Heckhausen, J., \& Dweck, C. S. (Eds.). (1998). Motivation and self-regulation across the life span. New York: Cambridge University Press.

Higgins, E. T. (1987). Self-discrepancy: A theory relating self and affect. Psychological Review, 94, 319-340.

Hoyle, R. H. (2000). Personality processes and problem behavior. Journal of Personality, 68, 953-966.

Hoyle, R. H., Fejfar, M. C., \& Miller, J. D. (2000). Personality and sexual risk-taking: A quantitative review. Journal of Personality, 68, 1203-1231.

Hoyle, R. H., \& Sowards, B. A. (1993). Self-monitoring and the regulation of social experience: A control-process model. Journal of Social and Clinical Psychology, 12, 280-306.

Hy, L. X., \& Loevinger, J. (1996). Measuring ego development (2nd ed.). Mahwah, NJ: Erlbaum.

Kagan, J. (1997). Temperament and reactions to the unfamiliar. Child Development, 68, 139-143.

Kochanska, G., Murray, K. T., \& Harlan, E. T. (2000). Effortful control in early childhood: Continuity and change, antecedents, and implications for social development. Developmental Psychology, 36, 220-232.

Krueger, R. F., Caspi, A., Moffitt, T. E., White, J., \& Stouthamer-Loeber, M. (1996). Delay of gratification, psychopathology, and personality: Is low self-control specific to externalizing problems? Journal of Personality, 64, 107-129.

Letzringa, T. D., Block, J., \& Funder, D. C. (2004). Ego-control and ego-resiliency: Generalization of self-report scales based on personality descriptions from self, acquaintances, and clinicians. Journal of Research in Personality, 39, 395-422.

Loevinger, J. (1976). Ego development: Conceptions and theories. San Francisco: Jossey-Bass.

Mischel, W. (1958). Preference for delayed reinforcement: An experimental study of a cultural observation. Journal of Abnormal and Social Psychology, 56, 57-61.

Mischel, W. (2004). Toward an integrative science of the person. Annual Review of Psychology, $55,1-22$.

Morf, C. C. (2006). Personality reflected in a coherent idiosyncratic interplay of intra- and interpersonal self-regulatory processes. Journal of Personality, 74, 1527-1556.

Morf, C. C., \& Rhodewalt, F. (2001). Expanding the dynamic self-regulatory processing model of narcissism: Research directions for the future. Psychological Inquiry, 12, 243-251.

Muraven, M. R., \& Baumeister, R. F. (2000). Self-regulation and depletion of limited resources: Does self-control resemble a muscle? Psychological Bulletin, 126, 247-259.

Paunonen, S. V., \& Ashton, M. C. (2001). Big five factors and facets and the prediction of behavior. Journal of Personality and Social Psychology, 81, 524-539.

Pyszczynski, T., \& Greenberg, J. (1987). Self-regulatory perseveration and the depressive self-focusing style: A self-awareness theory of reactive depression. Psychological Bulletin, 102, $122-138$. 
Roberts, B. W., Chernyshenko, O. S., Stark, S., \& Goldberg, L. R. (2005). The structure of conscientiousness: An empirical investigation based on seven major personality questionnaires. Personnel Psychology, 58, 103-139.

Rothbart, M. K., \& Rueda, M. R. (2005). The development of effortful control. In U. Mayr, E. Awh, \& S. Keele (Eds.), Developing individuality in the human brain: A tribute to Michael I. Posner (pp. 167-18). Washington, DC: American Psychological Association.

Spinella, M. (2004). Neurobehavioral correlates of impulsivity: Evidence of prefontal involvement. International Journal of Neuroscience, 114, 95-104.

Tellegen, A. (1982). A brief manual for the Multidimensional Personality Questionnaire. Unpublished manuscript, University of Minnesota.

Tobin, R. M., Graziano, W. G., Vanman, E. J., \& Tassinary, L. G. (2000). Personality, emotional experience, and efforts to control emotions. Journal of Personality and Social Psychology, 79, 656-669.

Wulfert, E., Block, J. A., Ana, E. S., Rodriguez, M. L., \& Colsman, M. (2002). Delay of gratification: Impulsive choices and problem behaviors in early and late adolescence. Journal of Personality, 70, 533-552.

Zuckerman, M., Kuhlman, D. M., Joireman, J., Teta, P., \& Kraft, M. (1993). A comparison of three structural models for personality: The big three, the big five, and the alternative five. Journal of Personality and Social Psychology, 65, 757-768. 